\title{
Management of Antimicrobial Agents in Abdominal Organ Transplant Patients in Intensive Care Unit
}

\author{
Aaron Kaviani $^{1} \cdot$ Dilek Ince $^{2} \cdot$ David A. Axelrod $^{1}$
}

Published online: 24 January 2020

(C) Springer Nature Switzerland AG 2020

\begin{abstract}
Purpose of Review Early diagnosis of infections and immediate initiation of appropriate antimicrobials are crucial in the management of patients before and after organ transplantation. We reviewed the most recent literature and guidelines in this field and organized the current recommendations for healthcare professionals caring for critically ill organ transplant recipients.

Recent Findings The incidence of multidrug-resistant organisms is increasing. Multidrug-resistant Gram-negative bacteria comprise about $14 \%$ of organisms. Vancomycin-resistant enterococci bloodstream infections are also on the rise, as $20.5 \%$ of nosocomial enterococci are now vancomycin-resistant, changing empiric antibiotic selection. Fluconazole-resistant Candida species comprise up to $46 \%$ of cases of candidemia in hospitalized patients. Consequently, new guidelines recommend primary use of echinocandins in patients with candidemia who have moderate-to-severe disease. Finally, the incidence of emergence of ganciclovir-resistant cytomegalovirus infection in patients is $5-12 \%$, requiring early recognition and change to alternative regimens in the case of poor response to therapy.

Summary Bloodstream infections are a major cause of mortality and morbidity in solid organ transplantation. Mortality as high as $24 \%$ and $50 \%$ have been reported with sepsis and septic shock respectively. As such, bloodstream infections should be diagnosed rapidly and intravenous antibiotics should be started immediately. Appropriate resuscitation should be initiated and the number and/or dose of immunosuppressive drugs should be reduced. Proper source control must also be achieved with radiologic drainage or surgical intervention as appropriate. Initial antibiotic treatment of these patients should cover both Grampositive organisms, especially in the presence of intravascular catheters, and Gram-negative bacteria. Echinocandins like caspofungin should also be considered especially in critically ill patients, particularly if a patient has been on total parenteral nutrition or broad-spectrum antibiotics.
\end{abstract}

Keywords Transplantation $\cdot$ Transplants $\cdot$ Critical care $\cdot$ Intensive care units $\cdot$ Infection $\cdot$ Antibacterial agents

\section{Abbreviations \\ BSI Blood stream infection \\ CDI Clostridium difficile infection \\ CMV Cytomegalovirus \\ CT Computed tomography \\ ERCP Endoscopic retrograde cholangiopancreatogram}

This article is part of the Topical Collection on Pancreas Transplantation

David A. Axelrod

david-axelrod@uiowa.edu

1 Organ Transplant Center, Department of Surgery, University of Iowa Hospitals \& Clinics, 200 Hawkins Drive, Iowa City, IA 52242, USA

2 Department of Internal Medicine, Division of Infectious Diseases, University of Iowa Hospitals \& Clinics, Iowa City, USA
ESLD End-stage liver disease

G-CSF Granulocyte colony-stimulating factor

IDSA Infectious Diseases Society of America

IFI Invasive fungal infection

IVIG Intravenous immunoglobulin

MELD Model of End-Stage Liver Disease

MRSA Methicillin-resistant Enterococcus

PMN Polymorphonuclear leukocyte

PTC Percutaneous cholangiogram

SBP Spontaneous bacterial peritonitis

SFP Spontaneous fungal peritonitis

SOT Solid organ transplant

SSI Surgical site infection

UTI Urinary tract infection

VRE Vancomycin-resistant Enterococcus 


\section{Introduction}

Organ transplantation is one of the major advances of modern medicine. The dream of replacing a nonfunctioning organ, like a kidney or a liver, with a functioning organ became a reality in 1954, when Dr. Joseph Murray transplanted a kidney from one identical twin to the other [1,2]. Over the past few years, there has been a significant improvement in survival and reduction in rejection after solid organ transplantation (SOT) as a result of more effective immunosuppression therapy. However, infections and particularly bloodstream infections (BSIs) still remain as a common complication and a major cause of death after transplant [3-5].

Transplant recipients have an increased risk of developing infections due to the lifelong treatment with immunosuppressive drugs [6]. Another risk factor for infection is the presence of unrecognized infection in the donor or the recipient. Rejection, which is often treated with intensified immunosuppression, also increases the incidence of infections, particularly viral and nosocomially acquired pathogens [3]. In addition, cytomegalovirus (CMV) infection may increase the risk of other infections, including bacterial and fungal infections $[3,7,8]$.

Bacterial infections are very common in patients with endorgan disease prior to and after SOT, and represent one of the most important causes of progression of liver failure, development of complications, and death in patients with end-stage liver disease (ESLD) [9]. Nosocomial bacterial infections are the most common cause of infection in this group of patients in the first month after transplantation $[3,5,10]$. Furthermore, liver, pancreas, and intestinal recipients are especially at risk for fatal fungal infections, primarily caused by Candida species which may occur together with bacterial infections. The risk of fungal infection is also higher in patients with kidney failure and history recent hospitalization. Candidemia is associated with diabetes, antibiotic use, total parenteral nutrition (TPN), surgical drains, and vascular access catheters. Delayed diagnosis because of low index of suspicion is common [11-14].

The complexity of treating SOT with life-threatening infections has been increasing dramatically given the increasing prevalence of multidrug-resistant organisms. Multidrugresistant Gram-negative bacteria comprise about $14 \%$ of organisms isolated in BSI after SOT. Recent studies show up to $20.5 \%$ of nosocomial enterococcal infections are vancomycinresistant. Fluconazole-resistant Candida species comprise up to $46 \%$ of cases of candidemia [12••, 15-17].

Early diagnosis of infections and timely initiation of adequate antimicrobials are crucial in the management of patients before and after transplantation [9]. Patients also require assessment and adjustment of their immunosuppression and subsequent comprehensive evaluation for the source of infection. The goal of this review is to provide concrete actionable guidelines for clinicians caring for abdominal SOT patients with serious infections.

\section{Infections Before Organ Transplantation}

Infections are a major barrier prior to organ transplantation and all potential candidates should be evaluated for active infection [18]. Although we usually have the luxury of treating infectious diseases in most transplant candidates well before transplantation, progressive organ failure in patients with ELSD may mandate aggressive treatment of their infectious disease and urgent liver transplantation.

Patients with ESLD are prone to infections due to abnormalities of their immune system and bacterial translocation from bowel. Bacterial infections may be an eliciting factor for episodes of hepatic encephalopathy, gastrointestinal bleeding, kidney failure, hyponatremia, and development of acute-on-chronic liver failure [9]. Infections are usually caused by Gram-negative bacteria from intestinal origin, but Gram-positive bacteria are also common, particularly in hospitalized patients [9]. Fungal infections, mainly caused by Candida species, can also occur and are associated with high mortality rates [19]. Spontaneous fungal peritonitis (SFP) is associated with higher mortality compared with spontaneous bacterial peritonitis (SBP) [20]. Candida albicans is the most frequent fungal agent followed by Cryptococcus neoformans and Aspergillus species. Clinicians should also consider the presence of polymicrobial fungal infections. In fact, while polymicrobial bacterial infections affect $5.2-17.4 \%$ of cases, polymicrobial fungal infections occurred in $73.3-100 \%$ of patients with systemic fungal infections in a small case series [20].

Due to high mortality and morbidity rate, SBP treatment should be initiated even in absence of a positive culture especially in patients with a higher Model for End-Stage Liver Disease (MELD) score. Patients with a positive fungal culture of the ascitic fluid regardless of polymorphonuclear leukocyte (PMN) count should also be treated. Antifungal drugs may also be started empirically for patients who are not responding to antibiotics [11]. Cefotaxime and ceftriaxone constitute the first-line treatment for community-acquired SBP and/or bacteremia, while broad-spectrum beta-lactams or carbapenems with or without vancomycin are considered the first-line treatment for nosocomial SBP and/or bacteremia [9]. Local resistance patterns should help guide empiric antibiotic therapy. Echinocandins like caspofungin should be considered empirical or preemptive therapy for patients with suspected SFP [20]. In patients with ESLD and SBP who are treated with antibiotics, intravenous administration of $20 \%$ albumin reduces the incidence of renal failure and decreased mortality rates from 29 to $10 \%$ [9]. Recommendations regarding empirical antibiotic treatment in patient with ESLD before liver transplantation have been summarized in Table 1 [9]. A personalized approach for first-line empiric antibiotic therapy needs to be chosen according to local epidemiology. 
Table 1 Initial antibiotic treatment in end-stage liver disease before liver transplantation [9, 21-23]

\begin{tabular}{|c|c|c|}
\hline Infection type & Community-acquired & Nosocomial \\
\hline $\begin{array}{l}\text { SBP } \\
\text { SBE } \\
\text { Spontaneous bacteremia }\end{array}$ & Cefotaxime or ceftriaxone & $\begin{array}{l}\text { Broad-spectrum beta-lactam- or carbapenem-based } \\
\text { therapy based on local antibiogram } \pm \text { vancomycin } \\
\text { (if high percentage of VSE/MRSA) }\end{array}$ \\
\hline Urinary infections with sepsis & Cefotaxime or ceftriaxone & $\begin{array}{l}\text { Broad-spectrum beta-lactam- or carbapenem-based } \\
\text { therapy based on local antibiogram } \pm \text { vancomycin } \\
\text { (if high percentage of VSE/MRSA) }\end{array}$ \\
\hline Pneumonia & $\begin{array}{l}\text { Ceftriaxone + macrolide or respiratory } \\
\text { fluoroquinolone (moxifloxacin or levofloxacin) }\end{array}$ & $\begin{array}{l}\text { Broad-spectrum beta-lactam- or carbapenem-based } \\
\text { therapy based on local antibiogram } \pm \text { vancomycin } \\
\text { (if high percentage of VSE/MRSA) }\end{array}$ \\
\hline Cellulitis & $\begin{array}{l}\text { Nonpurulent infection (necrotizing infection/ } \\
\text { cellulitis/erysipelas): } \\
\text { Severe: rule out necrotizing process; empiric } \\
\text { anti-MRSA agent +piperacillin/tazobactam } \\
\text { Moderate: ceftriaxone or cefazolin } \\
\text { Purulent cellulitis (furuncle/carbuncle/abscess): } \\
\text { Irrigation and debridement } \\
\text { Empiric: anti-MRSA agent }\end{array}$ & \\
\hline
\end{tabular}

SBP, spontaneous bacterial peritonitis; SFP, spontaneous fungal peritonitis; MRSA, methicillin-resistant Staphylococcus aureus; commonly administered anti-MRSA agents: vancomycin, daptomycin, linezolid, ceftaroline

\section{Infections After Organ Transplantation}

Infections after organ transplantation are commonly classified in 3 time periods: less than 1 month, first year, and after the first year.

\section{Infections in 1 Month After Transplantation}

The main sources of infection in the first month after SOT include donor-derived infections, preexisting recipient infections, surgical complications, and nosocomial infections including Clostridium difficile infection (CDI). Early removal of lines and drains, drainage of fluid collections, careful wound care, and judicious and limited use of antimicrobial agents help to reduce infections in this period of time [14, 24].

\section{Infections in 1 to 6-12 Months After Transplant}

The sources of infection in this period of time include surgical complications like anastomotic leaks, infected hematomas, cholangitis, and empyema as well as remaining nosocomial infections from previous month including CDI and residual pneumonia. Furthermore, opportunistic infections including viral infections, Pneumocystis jiroveci, Listeria monocytogenes, Toxoplasma gondii, Nocardia species, Aspergillus species, and endemic fungi usually happen in this period of time. Prophylactic measures are needed in this period of time to prevent opportunistic infections [14, 24].

\section{Infections Beyond 6-12 Months After Transplant}

The risk of infection is less in this period of time in recipients with good graft function due to lower intensity of immunosuppressive agents. Sources of infection during this period include community-acquired viruses, foodborne gastroenteritis, molds from work or gardening, primary socially acquired CMV infection, relapsing viral infection, and infections related to underlying conditions like skin infections in diabetics. Patients with marginal allograft function who need higher levels of maintenance immunosuppression need more attention because of increased risk of recurrent infections including pneumonia, urinary tract infections (UTIs), cholangitis, and abscesses [14, 24].

\section{Common Infections Specific to Different Organ Transplantations}

Infections are common after all types of SOT. However, some infections are more frequent in certain SOT recipients. In the following section, we address this issue in detail.

\section{Common Infections Specific to Kidney Transplantation}

The most common infections in kidney transplant recipients include UTI (47\%), viral infections (17\%), pneumonia (8\%), and wound infection (7\%). UTIs are most commonly caused by Enterococcus species and Escherichia coli are the most common agents [25]. Kidney allograft pyelonephritis may 
be associated with bacteremia and sepsis and can be complicated by impaired graft function and even death [26]. BK virus can cause graft failure in kidney transplant recipients. However, with universal screening and treatment, reported graft loss due to BKV is only 0 to $5 \%$. Careful immunosuppression adjustment is needed in these patients. Antiviral agents have a limited role. Intravenous immunoglobulin (IVIG) is occasionally used if there is persistent BK viremia after reduction of immunosuppression [27].

\section{Infections Specific to Pancreas Transplantation}

The most common sites of infection in pancreas recipients include urinary tract and wound infections. Intestinal leaks in patients with enteric drainage happen in 5 to $8 \%$ of cases, resulting in abdominal abscesses requiring surgical or radiologic intervention. Most infections in pancreas transplant recipients are bacterial [28]. These patients are also at a higher risk for getting fungal infections and CMV given the greater intensity of immunosuppression and long-standing diabetes $[12 \bullet \bullet, 28]$.

In case of enteric drained graft leak, an abdominal computerized tomography (CT) scan with oral contrast should be done. Treatment comprises laparotomy and anastomotic revision which may include conversion of the enteric anastomosis from a side-to-side duodenojejunostomy to a Roux-Yduodenojejunostomy or a transplant pancreatectomy. For an early ( $\leq 2$ weeks post-transplant) bladder-drained graft leak, low-pressure cystography or an abdominal CT with retrograde bladder contrast should be done. Foley catheter should be placed and percutaneous drainage of intraabdominal fluid collections should be performed. Peritonitis needs relaparotomy and direct leak repair or transplant pancreatectomy. Late leaks usually need conversion from bladder to enteric drainage [29].

\section{Infections Specific to Liver Transplantation}

Major infections develop in 53-56\% of liver transplant recipients $[30,31]$. Bacterial infections are most frequent $(70 \%)$, followed by viral (20\%) and fungal infections (8\%) [32•]. The most common bacterial infections include pneumonia, surgical site infection, abdominal cavity collections, abscesses, BSIs, and UTI [32•]. Many of these infections are associated with technical problems including bile duct stricture, biliary leaks, and hepatic artery thrombosis [15]. Laici and colleagues report pneumonia was the most frequent primary or associated infection and represented $40 \%$ of all infections after liver transplant. In $22 \%$ of cases, pneumonia led to the development of septic shock, which led to the death in more than $50 \%$ of affected recipients [32•]. Enterobacteriaceae are the major pathogens in LT recipients. Gram-positive bacteria are also a common cause infection [15]. LT recipients are also at a higher risk for getting fungal infections [12••].

\section{Common Infection Sites After Solid Organ Transplantation}

\section{Bloodstream Infections and Sepsis}

Bloodstream infections are the primary cause of mortality and morbidity in SOT. Mortality as high as $24 \%$ and $50 \%$ have been reported with sepsis and septic shock respectively. Nosocomial BSIs are associated with a higher rate of septic shock and mortality. Gram-positive bacteria are the most common cause of BSIs and tend to be associated with intravascular catheters. However, in kidney transplant recipients, Gramnegative bacteria are more common in BSIs, mostly associated with UTIs [12••, 16, 17, 33-37].

Intravenous antibiotics should be started immediately. Appropriate resuscitation with goal-directed therapy including monitoring of markers of adequacy (lactate, central venous saturation, and end-organ perfusion) should be achieved. Furthermore, in severely ill patients, clinicians should rapidly reduce the intensity of immunosuppression. This includes stopping antiproliferative agents (e.g., mycophenolate mofetil) and mTORs (e.g., rapamycin) and lowering calcineurin inhibitor levels. Corticosteroids should be maintained to prevent adrenal insufficiency. The role of granulocyte colonystimulating factor (G-CSF) drugs is controversial, and GCSF has been used by some centers for leukocyte counts of less than 3000 cells $/ \mathrm{mm}[3,38]$. Proper source control, if possible, should also be rapidly achieved with radiological drainage or surgical intervention.

Initial antibiotic treatment of SOT patients with BSI should include coverage for probable source(s). Especially in the presence of intravascular catheters, Gram-positive pathogen coverage with vancomycin should be added to Gramnegative pathogen coverage [12••, 39-41]. Linezolid or daptomycin instead of vancomycin should be considered if there is a recent history of vancomycin-resistant Enterococcus (VRE) colonization or infection. Prior microbiologic history and local antibiotic resistance patterns in addition to possible source of infection should guide antibiotic therapy [12••].

Echinocandins like caspofungin should also be considered in patients with septic shock without a focus especially in patients with risk factors for invasive candidiasis such as older age, central venous catheters, Candida colonization, total parenteral nutrition (TPN), prolonged neutropenia, prolonged intensive care unit stay, diabetes, renal replacement therapy, and/or broad-spectrum antibiotic therapy [42, 43]. Likewise, diagnosed candidemia requires treatment in all patients with either fluconazole or an echinocandin. One of the main differences between the newer vs. older guidelines is the primary use of echinocandins in patients with candidemia who have moderate-to-severe disease. However, empiric antifungal coverage is not needed if a patient does not meet above criteria $[12 \bullet, 39,44,45]$. Recommendations regarding initial 
antibiotic treatment of bloodstream infections and sepsis after SOT have been summarized in Table 2 [39, 42]. Initial management of different fungal infections after SOT has been summarized in Table $3[39,46,47]$.

\section{Respiratory Infections}

Bacterial pneumonia is the most common cause of pulmonary infection in SOT candidates. Timing after transplantation, age, transplanted organ, degree of immunosuppression, site of acquisition of pneumonia, and exposures all play into the differential diagnosis in solid organ transplant patients [48••]. Community-acquired pneumonia and hospital-acquired pneumonia account for $40.7 \%$ and $59.3 \%$ of pneumonias in SOT, respectively. Hospital- or ventilator-associated pneumonia are typically diagnosed in the early post-transplant period with Pseudomonas aeruginosa, Gram-negative enteric bacteria, Acinetobacter species, Stenotrophomonas species, and Staphylococcus aureus, including MRSA as the most common pathogens in the peri-operative period. Opportunistic infections are most commonly seen in 1-6 months after transplant, and community-acquired pathogens, such as Streptococcus pneumoniae, Haemophilus influenzae, Mycoplasma species, Legionella species, and Chlamydia species, are more frequent after 6 months, though opportunistic infections can still be seen, especially if immunosuppression is increased for treatment of rejection.
Empiric treatment for pneumonia needs to be based on the above risk factors and timing after transplantation as well as the pace of illness onset. In nosocomial or ventilatorassociated pneumonia, nosocomial flora, and antibiogram and in lung transplant patients or in patients with prior pulmonary infections, organisms colonizing the airways and their susceptibilities should also be taken into consideration. For hospital-associated pneumonia and ventilator-associated pneumonia, The ID Society of America and American Society of Transplantation guidelines on pneumonia should be followed in conjunction with local antibiogram [48••, 49]. Broad-spectrum antibiotics with an activity against $P$. aeruginosa and other Gram-negative bacilli should be started empirically. For patients with septic shock and need for new ventilatory support, two agents with activity against $P$. aeruginosa can be considered. In patients with a high risk of mortality, prior intravenous antibiotic use within 90 days, hospitalization in a unit with $>20 \%$ MRSA prevalence, an antiMRSA agent should also be started empirically. Empiric treatment should be modified based on previous microbiologic history and local antibiogram as well as patient's clinical response. An active agent against intracellular organisms and during the influenza season, anti-influenza agents are also recommended for empiric treatment until these infections are ruled out.

Respiratory viral infections, including CMV, are important causes of pneumonia among transplant recipients. Viral pneumonia predisposes the patient to superinfection with bacterial
Table 2 Initial antibiotic treatment of bloodstream infections and sepsis after organ transplantation [39, 42]

\begin{tabular}{|c|c|}
\hline Infection type & Treatment \\
\hline Fever without a clear focus & $\begin{array}{l}\text { Broad-spectrum beta-lactam/beta-lactamase inhibitor such as } \\
\text { piperacillin/tazobactam based on local antibiogram. Narrow empiric coverage } \\
\text { within } 48 \mathrm{~h} \text { if no source and negative cultures* }\end{array}$ \\
\hline \multirow{4}{*}{$\begin{array}{l}\text { Septic shock without a clear } \\
\text { focus }\end{array}$} & Broad-spectrum Gram-negative coverage + anti-MRSA agent \\
\hline & Consider adding caspofungin $* * *$ \\
\hline & $\begin{array}{l}\text { If a patient has severe penicillin allergy: aztreonam }+ \text { vancomycin } * *+ \\
\text { metronidazole } \pm \text { aminoglycoside }\end{array}$ \\
\hline & Consider adding caspofungin $* * *$ \\
\hline \multirow[t]{2}{*}{$\begin{array}{l}\text { Intravascular } \\
\text { catheter-related infection }\end{array}$} & $\begin{array}{l}\text { Gram-positive (anti-MRSA and depending on risk factors, anti-VRE coverage + } \\
\text { broad-spectrum Gram-negative coverage (broad-spectrum beta-lactam or } \\
\text { carbapenem)) }\end{array}$ \\
\hline & $\begin{array}{l}\text { If a patient has severe penicillin allergy: Gram-positive (anti-MRSA and } \\
\text { depending on risk factors, anti-VRE coverage + aztreonam or } \\
\text { ciprofloxacin } * * * * \pm \text { aminoglycoside) }\end{array}$ \\
\hline Candidemia & Caspofungin \\
\hline
\end{tabular}

$V R E$, vancomycin-resistant enterococci; $T P N$, total parenteral nutrition

*In this group, if a patient is not neutropenic, we may hold antibiotics during initial evaluation

**Consider linezolid or daptomycin instead of vancomycin if there is a recent history of VRE colonization or infection

***Consider caspofungin especially if there is Candida colonization or if a patient is on TPN or if a patient has been on broad-spectrum antibiotics recently

$* * * *$ Based on local antibiogram 
Table 3 Initial management of different fungal infections after organ transplantation [39, 46, 47]

\begin{tabular}{|c|c|}
\hline Type & Management \\
\hline \multirow[t]{4}{*}{$\begin{array}{l}\text { Asymptomatic candiduria } \\
\text { and UTI }\end{array}$} & $\begin{array}{l}\text { Asymptomatic candiduria does not need medical treatment } \\
\text { unless a patient is neutropenic or is going to have urologic } \\
\text { procedures }\end{array}$ \\
\hline & $\begin{array}{l}\text { UTI should be treated with fluconazole if Candida sp. is } \\
\text { azole-resistant; amphotericin B lipid complex or liposomal } \\
\text { amphotericin B can be used }\end{array}$ \\
\hline & Urinary catheter needs to be removed \\
\hline & Fungal balls should be removed \\
\hline \multirow[t]{3}{*}{ Invasive candidiasis } & Central venous catheters need to be removed \\
\hline & Mild disease can be treated with fluconazole \\
\hline & $\begin{array}{l}\text { Moderate and severe diseases should to be treated with } \\
\text { echinocandins like caspofungin. It can be switched to oral } \\
\text { fluconazole once a patient is stable and all cultures are } \\
\text { negative }\end{array}$ \\
\hline \multirow[t]{3}{*}{ Invasive aspergillosis } & Voriconazole is the preferred treatment \\
\hline & $\begin{array}{l}\text { Immunosuppression especially corticosteroid dose should } \\
\text { be reduced }\end{array}$ \\
\hline & $\begin{array}{l}\text { Surgery is indicated if there is sinus disease, massive } \\
\text { hemoptysis, endocarditis, pericardial disease, and large } \\
\text { vessel involvement }\end{array}$ \\
\hline \multirow[t]{3}{*}{ Mucormycosis } & Lipid formulation amphotericin B should be started \\
\hline & Immunosuppression should be reduced \\
\hline & Affected tissue should be surgically removed \\
\hline \multirow[t]{4}{*}{ Cryptococcal infection } & $\begin{array}{l}\text { Liposomal amphotericin B or amphotericin B lipid complex } \\
\text { plus flucytosine should be started. After } 2 \text { weeks, it can } \\
\text { be switched to fluconazole }\end{array}$ \\
\hline & Immunosuppression should be reduced \\
\hline & If ICP $>25$, lumbar puncture should be done \\
\hline & Infectious disease consult should be obtained \\
\hline
\end{tabular}

UTI, urinary tract infection; $I C P$, intracranial pressure and fungal pneumonia. Treatment includes supportive care and reduction in immunosuppression (see CMV treatment below) $[12 \bullet \bullet$.

SOT recipients have a significant risk of invasive fungal infections (IFIs). Small bowel transplant recipients followed by heart-lung, liver, and pancreas transplant recipients have the highest rate of IFIs respectively [39, 46]. Although Candida species remain the most common cause of IFIs in SOT, molds comprise approximately $40 \%$ of IFIs in this group of patients. Aspergillus species cause the majority of mold infections. Mucormycosis is the next most common mold infection. Cryptococcosis and endemic fungi are other etiologies for IFIs $[39,47]$. Echinocandins like caspofungin are recommended for treatment of Candida sp. However, the Infectious Diseases Society of America (IDSA) guidelines recommend voriconazole as the treatment of choice for invasive aspergillosis with isavuconazole and amphotericin B listed as alternative agents [50]. High-dose lipid formulation amphotericin B is recommended for mucormycosis, in combination with aggressive surgical debridement of infected tissues [39]. Recommendations regarding initial antibiotic treatment of respiratory infections after SOT have been summarized in Table 4 [39, 42]. Initial management of different fungal infections after SOT has been summarized in Table $3[39,46,47]$.

\section{Central Nervous System Infections}

Central nervous system infections can be caused by donorderived infections, community-acquired organisms, and reactivation and/or acquisition of opportunistic pathogens. Cryptococcus, Nocardia, Aspergillus, Zygomycetes, Strongyloides, and Toxoplasma can affect both the lungs and the brain [12]. Clinical presentation depends on the organism, but may be subtle due to lack of a robust immune system. History; physical examination including detailed neurologic examination; laboratory evaluation including viral polymerase chain assays or multiplex panels; serum cryptococcal antigen; blood, urine, and sputum cultures; chest radiograph; magnetic resonance imaging of the brain with contrast; lumbar puncture; electroencephalography for seizures; and possibly neurosurgical intervention including biopsy and debridement are key elements in the evaluation of these patients [51]. 
Table 4 Initial antibiotic treatment of respiratory infections after organ transplantation $[39,42]$

\begin{tabular}{ll}
\hline Infection type & Treatment \\
\hline Nosocomial sinusitis & $\begin{array}{c}\text { Broad-spectrum beta-lactam agent } \\
\text { based on local antibiogram } \\
\text { Broad-spectrum beta-lactam agent } \\
\text { based on antibiogram plus } \\
\text { pneumonia } \\
\text { intracellular active agent plus } \\
\text { vancomycin or linezolid } \\
\text { Consider IV TMP/SMX based on } \\
\text { clinical and radiologic findings if } \\
\text { not on PJP prophylaxis* }\end{array}$ \\
$\begin{array}{c}\text { Caspofungin } \\
\text { Invasive pulmonary } \\
\text { candidiasis }\end{array}$ & Voriconazole \\
aspergillosis & \\
\hline
\end{tabular}

$I V$, intravenous; $T M P / S M X$, trimethoprim/sulfamethoxazole; $P J P$, pneumocystis jiroveci pneumonia

*Especially within first year after transplant

Recommendations regarding initial antibiotic treatment of central nervous system infections after SOT have been summarized in Table 5 [42]. A recently published Cochrane review did not show sufficient evidence in favor or against primary and secondary preventions of seizures with anticonvulsive agents in viral encephalitis; however, some experts continue to recommend antiepileptic medications in all patients with seizures and encephalitis [52].

\section{Urinary Infections}

UTIs are the most common infection after organ transplantation and account for 45 to $72 \%$ of all infections and $30 \%$ of all hospitalizations due to sepsis in kidney transplant recipients. Complicated UTI including pyelonephritis can result in significantly impaired transplanted kidney function and even death $[12 \bullet \bullet, 26]$. While Gram-negative bacilli are the most common cause of UTIs, Enterococcus sp. and S. aureus can also lead to UTIs in patients with indwelling urinary catheters $[12 \bullet \cdot$. Broad-spectrum antibiotics such as piperacillin/ tazobactam or carbapenems might be warranted, with deescalation based on culture results [42, 53]. Patient's history of prior urinary tract infections and the organisms identified also need to be considered. In severe infections such as septic shock, immunosuppression should be reduced and upper tract imaging should be obtained. Cystoscopic, percutaneous, or surgical procedures to relieve obstruction or to drain abscesses might be needed [53].

Candida is the most common cause of fungal UTI in kidney transplant recipients. Asymptomatic candiduria occurs in $11 \%$ of kidney transplant and does not require treatment. In these situations, urinary catheters should be removed or exchanged and second urine sample should be collected. Persistent candiduria in patients who does not have urinary catheter needs upper urinary tract imaging to evaluate for anatomic abnormalities and fungus balls. Asymptomatic candiduria should not be treated. Fluconazole is the treatment of choice for UTIs with susceptible Candida sp. Echinocandins are considered to be drugs of choice in unstable patients with systemic candidiasis; however, they do not reach acceptable levels for treatment of UTIs and relapses may occur. Recommendations regarding initial antibiotic treatment of urinary infections after SOT have been summarized in Table 6 [42].

\section{Hepatobiliary Infections}

Bile leak, biloma, and biliary stricture can occur after liver transplantation especially after living donor liver transplants and can be complicated by peritonitis, abscess, and cholangitis. Hepatic artery thrombosis can lead to biliary complications as well as hepatic necrosis, abscesses, and sepsis. Cholangitis is a common complication after liver
Table 5 Initial antibiotic treatment of central nervous system infections after organ transplantation [42]

\begin{tabular}{ll}
\hline Infection type & Treatment \\
\hline $\begin{array}{l}\text { Acute } \\
\text { meningitis/- } \\
\text { meningoencephalitis }\end{array}$ & Empiric treatment depends on clinical situation and most likely diagnosis \\
Subacute/chronic meningitis & Ceftriaxone + vancomycin + ampicillin* \pm acyclovir or ganciclovir \\
& Consider adding lipid amphotericin if clinical suspicion for cryptococcal \\
infection** & Consider ganciclovir if there is CSF lymphocytic pleocytosis*** \\
& Consider doxycycline in endemic area for rocky mountain spotted fever \\
& Depends on clinical situation and most likely diagnosis \\
& Meropenem \pm vancomycin \\
Brain abscess & Consider adding voriconazole or lipid formulation amphotericin \\
\end{tabular}

$C S F$, cerebrospinal fluid; TMP/SMX, trimethoprim/sulfamethoxazole

*For Listeria, especially if a patient is not on TMP/ SMX

**While waiting for cryptococcal test results

****Especially if encephalopathic 
Table 6 Initial antibiotic treatment of intraabdominal and gastrointestinal infections after organ transplantation $[42,53]$

\begin{tabular}{|c|c|}
\hline Infection type & Treatment \\
\hline $\begin{array}{l}\text { Urinary tract infection (complicated } \\
\text { UTI/pyelonephritis; moderate to severe) }\end{array}$ & Broad-spectrum beta-lactam agent or carbapenem* \\
\hline \multirow[t]{3}{*}{ Liver abscess or cholangitis } & $\begin{array}{l}\text { Broad-spectrum beta-lactam agent/carbapenem + anti-MRSA } \\
\text { coverage+ metronidazole }\end{array}$ \\
\hline & May consider adding fluconazole or caspofungin \\
\hline & Antifungals should be added if there is infected biloma \\
\hline \multirow[t]{7}{*}{ Peritonitis or intraabdominal abscess } & $\begin{array}{l}\text { Broad-spectrum beta-lactam agent/carbapenem with } \\
\text { antipseudomonal activity }\end{array}$ \\
\hline & $\begin{array}{l}\text { Add anaerobic coverage in cases of distal small } \\
\text { bowel/appendiceal or colonic infections and gastrointestinal } \\
\text { perforation }\end{array}$ \\
\hline & Consider empiric anti-MRSA agent after liver transplant \\
\hline & $\begin{array}{l}\text { Antifungals should be added after liver and pancreas transplant } \\
\text { or in patients with bowel leak, perforations, and septic shock }\end{array}$ \\
\hline & $\begin{array}{l}\text { If a patient has severe penicillin allergy: vancomycin }+ \\
\text { metronidazole }+ \text { aztreonam }\end{array}$ \\
\hline & May consider adding fluconazole or caspofungin \\
\hline & If VRE positive: add linezolid or daptomycin \\
\hline \multirow[t]{4}{*}{ Enterocolitis } & $\begin{array}{l}\text { If high risk for } \mathrm{C} \text { difficile (recent antibiotic therapy or severe } \\
\text { illness): oral vancomycin until } C \text {. difficile testing result is } \\
\text { available }\end{array}$ \\
\hline & $\begin{array}{l}\text { Consider broad-spectrum beta-lactam ( } \pm \text { beta-lactamase } \\
\text { inhibitor) }\end{array}$ \\
\hline & Consider ganciclovir in high-risk patients \\
\hline & CMV-IG may be added after intestinal transplant \\
\hline \multirow[t]{2}{*}{ Esophagitis } & Fluconazole or caspofungin \\
\hline & $\begin{array}{l}\text { If suspect viral infection, consider valganciclovir or ganciclovir } \\
\text { if severe }\end{array}$ \\
\hline
\end{tabular}

$U T I$, urinary tract infection; $V R E$, vancomycin-resistant enterococci; $C M V$, cytomegalovirus intravenous immune; $C M V-I G$, cytomegalovirus intravenous immune globulin

*Based on prior UTI organisms and susceptibilities transplantation and is the most common infection after the first year after liver transplant. Cholangitis is more common in patients with primary sclerosing cholangitis and Roux-en-Y biliary reconstruction. The most common bacteria are Enterococcus species and E. coli. Other Gram-negative bacilli and anaerobes and vancomycin-resistant Enterococcus faecium (VRE) should be considered in these patients [12••].

Broad-spectrum Gram-negative coverage with also anaerobic activity should be started in patients with sepsis. Specific regimen needs to be tailored to the local antibiogram and follow institutional empiric treatment guidelines, which take into consideration institutional rates of extended-spectrum beta-lactamase- or carbapenemase-producing organisms as well as multidrug-resistant $P$. aeruginosa. If a patient has peritonitis or intraabdominal abscess, Gram-positive coverage (vancomycin or daptomycin in patients with history of VRE) and antifungals should be added [42, 54]. If there are any concerns for biliary stricture(s) or bile leak based on initial imaging, endoscopic retrograde cholangiopancreatography (ERCP) should be performed and stent(s) placement might be needed. Percutaneous transhepatic cholangiogram (PTC) is reserved for ERCP failure or conditions that preclude it like Roux-en-Y hepaticojejunostomy or gastric outlet obstruction . Recommendations regarding initial antibiotic treatment of hepatobiliary infections after SOT have been summarized in Table 6 [42].

\section{Enterocolitis}

Diarrhea occurs in 22 to $52 \%$ of SOT patients and can be due to infectious causes including bacterial, viral, or parasitic infections as well as medications including mycophenolate mofetil side effect. Stool culture, ova and parasite testing, and multiplex PCR testing for a wide variety of pathogens, if available, are among the initial tests recommended. Imaging studies and endoscopy (esophagogastroduodenoscopy and/or colonoscopy) may be warranted $[12 \bullet \bullet]$.

Clostridium difficile infection is the most common hospital-acquired infectious diarrhea, and fulminant colitis can happen in up to $13 \%$ of recipients with CDI [12••]. Oral 
vancomycin and fidaxomicin are currently the first-line therapies for an initial episode of CDI. Oral metronidazole is only recommended for an initial episode of nonsevere CDI if oral vancomycin and fidaxomicin are not available [55]. Fidaxomicin has similar efficacy to vancomycin and has been associated with decreased rates of recurrent infection in immunocompetent patients; however, there is limited data on its efficacy in solid organ transplant patients [56••]. For fulminant $\mathrm{CDI}$, oral vancomycin (or rectal vancomycin for cases with ileus) in conjunction with intravenous metronidazole is recommended. Subtotal colectomy with ileostomy is the standard of care when toxic megacolon, perforation, or an acute surgical abdomen is present. Leukocytosis $>50,000 / \mu \mathrm{L}$, lactate $\geq$ $5 \mathrm{mmol} / \mathrm{L}$, and hypoalbuminemia are associated with impending shock. Urgent colectomy should be considered in these patients [57]. Fecal microbiota transfer is recommended in immunocompetent patients with multiple recurrence of CDI. Retrospective studies have reported efficacy and safety in SOT patients with recurrent CDI. Bezlotoxumab, a humanized monoclonal antibody against $C$. difficile toxin $\mathrm{B}$, can be given to SOT patients with recurrent episodes of CDI [56••].

CMV colitis can occur after SOT and can potentially cause end-organ disease. Treatment includes oral valganciclovir or intravenous ganciclovir [12•*]. While the incidence of ganciclovirresistant cytomegalovirus in patients on prophylactic valganciclovir is as low as $0-3 \%$, the incidence of emergence of ganciclovir-resistant cytomegalovirus infection in patients receiving ganciclovir treatment is about $5-12 \%$ [58]. For patients whose viral loads fail to decline while on therapy, ganciclovir resistance test is recommended. For most patients with confirmed ganciclovir resistance, foscarnet is suggested [59]. Cidofovir is the other option when there is a concern for resistance [12••]. Letermovir has also shown promising results in these patients, though it has not been approved yet for this indication $[60,61]$. CMV immunoglobulin is associated with limited efficacy $[12 \bullet \cdot$. Recommendations regarding initial antibiotic treatment of enterocolitis after SOT have been summarized in Table 6 [42].

\section{Wound Infection}

Surgical site infections (SSIs) are a common and major complication in SOT and are reported to occur in $5-40 \%$ of these patients [62]. Risk factors for SSI following various organ transplant surgeries and the most common pathogens have been summarized by Abbo et al. [63]. Infected wounds should be opened and washed out. Imaging for evaluation of possible deeper abscess should be performed and aspirates from these collections should be sent for cultures are recommended [42]. Source control is needed for treatment of deep SSIs and organ space infections. For SSIs, empiric treatment should include Gram-positive organisms as well as expected flora at site of
Table 7 Initial antibiotic treatment of would infection after organ transplantation [42]

\begin{tabular}{ll}
\hline Infection type & Treatment \\
\hline Cellulitis & Purulent cellulitis: vancomycin \\
$\begin{array}{l}\text { Would infection after } \\
\text { bowel transplant }\end{array}$ & $\begin{array}{c}\text { Broad-spectrum beta-lactam } \\
( \pm \text { beta-lactamase inhibitor }) \\
\end{array}$ \\
& or carbapenem plus \\
& anti-MRSA agent \\
\hline
\end{tabular}

transplanted organ, with broad-spectrum agents reserved for patients with risk for multidrug-resistant organisms [63].

Recommendations regarding initial antibiotic treatment of wound infection after SOT have been summarized in Table 7.

\section{Conclusion}

Transplant recipients have an increased risk of developing infections due to the lifelong treatment with immunosuppressive drugs. There should be a high index of suspicion in these patients and infections should be diagnosed rapidly. Early imaging is required. A multidisciplinary approach to the management of these patients which should include transplant surgery, infectious disease, and possibly interventional radiology as well as gastroenterology is needed. Appropriate resuscitation should be initiated and intravenous antibiotics should be started immediately. The number and/or dose of immunosuppressive drugs should be reduced. Proper source control must also be achieved with radiologic drainage or surgical intervention.

\section{Compliance with Ethical Standards}

Conflict of Interest The authors declare that they have no conflict of interest.

Human and Animal Rights and Informed Consent This article does not contain any studies with human or animal subjects performed by any of the authors.

\section{References}

Papers of particular interest, published recently, have been highlighted as:

- Of importance

•• Of major importance

1. Jonsen AR. The birth of bioethics. Oxford University Press; 2003.

2. Jonsen AR. The ethics of organ transplantation: a brief history. Virtual Mentor. 2012;14(3):264-8. 
3. Grim SA, Clark NM. Management of infectious complications in solid-organ transplant recipients. Clin Pharmacol Ther. 2011;90(2): 333-42.

4. Sayegh MH, Carpenter CB. Transplantation 50 years later-progress, challenges, and promises. N Engl J Med. 2004;351(26):27616.

5. Torbenson M, Wang J, Nichols L, Jain A, Fung J, Nalesnik MA. Causes of death in autopsied liver transplantation patients. Mod Pathol. 1998;11(1):37-46

6. Tiago Silva J, López-Medrano F, Aguado JM. Highlights in solid transplant infectious diseases 2015-2017. Rev Esp Quimioter. 2018;(31 Suppl 1, Suppl 1):52-5.

7. Paya CV, Wiesner RH, Hermans PE, et al. Risk factors for cytomegalovirus and severe bacterial infections following liver transplantation: a prospective multivariate time-dependent analysis. $\mathrm{J}$ Hepatol. 1993;18(2):185-95.

8. Hodson EM, Jones CA, Webster AC, et al. Antiviral medications to prevent cytomegalovirus disease and early death in recipients of solid-organ transplants: a systematic review of randomised controlled trials. Lancet. 2005;365(9477):2105-15.

9. Jalan R, Fernandez J, Wiest R, et al. Bacterial infections in cirrhosis: a position statement based on the EASL Special Conference 2013. J Hepatol. 2014;60(6):1310-24 This study presents a thorough review of bacterial infections in cirrhosis, including diagnosis, prophylaxis, and treatment.

10. Kusne S, Dummer JS, Singh N, Iwatsuki S, Makowka L, Esquivel C, et al. Infections after liver transplantation. An analysis of 101 consecutive cases. Medicine. 1988;67(2):132-43.

11. Alexopoulou A, Vasilieva L, Agiasotelli D, Dourakis SP. Fungal infections in patients with cirrhosis. J Hepatol. 2015;63(4):1043-5.

12.• Guenette A, Husain S. Infectious complications following solid organ transplantation. Crit Care Clin. 2019;35(1):151-68 This article is another up-to-date comprehensive review of infections that can be observed in intensive care units in solid organ transplant patients.

13. Pappas PG, Alexander BD, Andes DR, et al. Invasive fungal infections among organ transplant recipients: results of the TransplantAssociated Infection Surveillance Network (TRANSNET). Clin Infect Dis. 2010;50(8):1101-11.

14. Fishman JA. Infection in organ transplantation. Am J Transplant Off J Am Soc Transplant Am Soc Transplant Surg. 2017;17(4): 856-79.

15. Kim SI. Bacterial infection after liver transplantation. World $\mathbf{J}$ Gastroenterol. 2014;20(20):6211-20.

16. Moreno A, Cervera C, Gavalda J, et al. Bloodstream infections among transplant recipients: results of a nationwide surveillance in Spain. Am J Transplant Off J Am Soc Transplant Am Soc Transplant Surg. 2007;7(11):2579-86.

17. Bodro M, Sabe N, Tubau F, et al. Risk factors and outcomes of bacteremia caused by drug-resistant ESKAPE pathogens in solidorgan transplant recipients. Transplantation. 2013;96(9):843-9.

18. Patel R, Paya CV. Infections in solid-organ transplant recipients. Clin Microbiol Rev. 1997;10(1):86-124.

19. Righi E. Management of bacterial and fungal infections in end stage liver disease and liver transplantation: current options and future directions. World J Gastroenterol. 2018;24(38):4311-29.

20. Fiore M, Leone S. Spontaneous fungal peritonitis: epidemiology, current evidence and future prospective. World J Gastroenterol. 2016;22(34):7742-7.

21. Rostkowska KA, Szymanek-Pasternak A, Simon KA. Spontaneous bacterial peritonitis - therapeutic challenges in the era of increasing drug resistance of bacteria. Clin Exp Hepatol. 2018;4(4):224-31.

22. Dionigi E, Garcovich M, Borzio M, Leandro G, Majumdar A, Tsami A, et al. Bacterial infections change natural history of cirrhosis irrespective of liver disease severity. Am J Gastroenterol. 2017;112(4):588-96.
23. Botwin GJ, Morgan TR. Bacterial infections in cirrhosis. Hepatol Int. 2014;8(Suppl 2):467-74.

24. Cohen-Bucay A, Gordon C, Francis J. Non-immunological complications following kidney transplantation [version 1; peer review: 3 approved]. F1000Research. 2019;8(194).

25. Alangaden GJ, Thyagarajan R, Gruber SA, et al. Infectious complications after kidney transplantation: current epidemiology and associated risk factors. Clin Transpl. 2006;20(4):401-9.

26. Issue $\mathrm{S}$. KDIGO clinical practice guideline for the care of kidney transplant recipients. Am J Transplant. 2009;9(s3):S1-S155.

27. Elfadawy N, Yamada M, Sarabu N. Management of BK polyomavirus infection in kidney and kidney-pancreas transplant recipients: a review article. Infect Dis Clin N Am. 2018;32(3):599-613.

28. Meirelles Júnior RF, Salvalaggio P, Pacheco-Silva A. Pancreas transplantation: review. Einstein (Sao Pau). 2015;13(2):305-9.

29. Troppmann C. Complications after pancreas transplantation. Curr Opin Organ Transplant. 2010;15(1):112-8.

30. Paya CV, Hermans PE, Washington JA 2nd, et al. Incidence, distribution, and outcome of episodes of infection in 100 orthotopic liver transplantations. Mayo Clin Proc. 1989;64(5):555-64.

31. Wade JJ, Rolando N, Hayllar K, Philpott-Howard J, Casewell MW, Williams R. Bacterial and fungal infections after liver transplantation: an analysis of 284 patients. Hepatology. 1995;21(5):1328-36.

32. Laici C, Gamberini L, Bardi T, Siniscalchi A, Reggiani MLB, Faenza S. Early infections in the intensive care unit after liver transplantation-etiology and risk factors: a single-center experience. Transpl Infect Dis. 2018;20(2):e12834 This study reports a single-center experience of early (within 1 month) infections after liver transplantation and evaluates donor and recipient risk factors for early infection.

33. Paterson DL, Dominguez EA, Chang FY, Snydman DR, Singh N. Infective endocarditis in solid organ transplant recipients. Clin Infect Dis. 1998;26(3):689-94.

34. Ruttmann E, Bonatti H, Legit C, Ulmer H, Stelzmueller I, Antretter $\mathrm{H}$, et al. Severe endocarditis in transplant recipients-an epidemiologic study. Transpl Int. 2005;18(6):690-6.

35. Berenger BM, Doucette K, Smith SW. Epidemiology and risk factors for nosocomial bloodstream infections in solid organ transplants over a 10-year period. Transpl Infect Dis. 2016;18(2):18390.

36. Silva M Jr, Marra AR, Pereira CA, Medina-Pestana JO, Camargo LF. Bloodstream infection after kidney transplantation: epidemiology, microbiology, associated risk factors, and outcome. Transplantation. 2010;90(5):581-7.

37. Candel FJ, Grima E, Matesanz M, Cervera C, Soto G, Almela M, et al. Bacteremia and septic shock after solid-organ transplantation. Transplant Proc. 2005;37(9):4097-9.

38. Page AV, Liles WC. Granulocyte colony-stimulating factor, granulocyte-macrophage colony-stimulating factor, and other immunomodulatory therapies for the treatment of infectious diseases in solid organ transplant recipients. Curr Opin Organ Transplant. 2008;13(6):575-80.

39. Vazquez JA, Miceli MH, Alangaden G. Invasive fungal infections in transplant recipients. Therapeutic advances in infectious disease. 2013;1(3):85-105.

40. Kalil AC, Dakroub H, Freifeld AG. Sepsis and solid organ transplantation. Curr Drug Targets. 2007;8(4):533-41.

41. Bafi AT, Tomotani DY, de Freitas FG. Sepsis in solid-organ transplant patients. Shock (Augusta, Ga). 2017;47(1S Suppl 1):12-6.

42. Kumar D, Humar A. AST handbook of transplant infections. Hoboken, UNITED KINGDOM: John Wiley \& Sons, Incorporated; 2011.

43. Aslam S, Rotstein C, Practice ASTIDCo. Candida infections in solid organ transplantation: guidelines from the American Society of Transplantation Infectious Diseases Community of Practice. Clin Transpl. 2019:e13623. 
44. Schuster MG, Edwards JE Jr, Sobel JD, et al. Empirical fluconazole versus placebo for intensive care unit patients: a randomized trial. Ann Intern Med. 2008;149(2):83-90.

45. Timsit JF, Azoulay E, Schwebel C, Charles PE, Cornet M, Souweine B, et al. Empirical micafungin treatment and survival without invasive fungal infection in adults with ICU-acquired sepsis, Candida colonization, and multiple organ failure: the EMPIRICUS randomized clinical trial. Jama. 2016;316(15): 1555-64.

46. Gavalda J, Meije Y, Fortun J, et al. Invasive fungal infections in solid organ transplant recipients. Clin Microbiol Infect. 2014;20(Suppl 7):27-48.

47. Khan A, El-Charabaty E, El-Sayegh S. Fungal infections in renal transplant patients. J Clin Med Res. 2015;7(6):371-8.

48.• Dulek DE, Mueller NJ, Practice ASTIDCo. Pneumonia in solid organ transplantation: guidelines from the American Society of Transplantation Infectious Diseases Community of Practice. Clin Transpl. 2019:e13545. This is the American Society of Transplantation ID Community's updated guideline on pneumonia in solid organ transplant patients, reviewing potential pathogens, differential diagnosis, diagnostic strategies, and empiric treatment options.

49. Kalil AC, Metersky ML, Klompas M, et al. Management of adults with hospital-acquired and ventilator-associated pneumonia: 2016 clinical practice guidelines by the Infectious Diseases Society of America and the American Thoracic Society. Clin Infect Dis. 2016;63(5):e61-e111.

50. Husain S, Camargo JF. Invasive aspergillosis in solid-organ transplant recipients: guidelines from the American Society of Transplantation Infectious Diseases Community of Practice. Clin Transpl. 2019:e13544.

51. Wright AJ, Fishman JA. Central nervous system syndromes in solid organ transplant recipients. Clin Infect Dis. 2014;59(7):1001-11.

52. Bradshaw MJ, Venkatesan A. Herpes simplex virus-1 encephalitis in adults: pathophysiology, diagnosis, and management. Neurotherapeutics. 2016;13(3):493-508.

53. Goldman JD, Julian K. Urinary tract infections in solid organ transplant recipients: guidelines from the American Society of Transplantation Infectious Diseases Community of Practice. Clin Transpl. 2019:e13507.

54. Haidar G, Green M, American Society of Transplantation Infectious Diseases Community of P. Intra-abdominal infections in solid organ transplant recipients: guidelines from the American Society of Transplantation Infectious Diseases Community of Practice. Clin Transpl. 2019:e13595.
55. McDonald LC, Gerding DN, Johnson S, et al. Clinical practice guidelines for Clostridium difficile infection in adults and children: 2017 update by the Infectious Diseases Society of America (IDSA) and Society for Healthcare Epidemiology of America (SHEA). Clin Infect Dis. 2018;66(7):987-94.

$56 . \bullet$ Mullane KM, Dubberke ER, Practice AICo. Management of Clostridioides (formerly Clostridium) difficile infection (CDI) in solid organ transplant recipients: Guidelines from the American Society of Transplantation Community of Practice. Clin Transpl. 2019:e13564. .This recent guideline from AST ID Community provides updates on newer treatment options, such as bezlotuxumab and fecal microbiota restoration therapy/fecal transplantation for $C$. difficile treatment in solid organ transplant patients.

57. Seltman AK. Surgical management of Clostridium difficile colitis. Clin Colon Rectal Surg. 2012;25(4):204-9.

58. Rolling KE, Jorgenson MR, Descourouez JL, Mandelbrot DA, Redfield RR, Smith JA. Ganciclovir-resistant cytomegalovirus infection in abdominal solid organ transplant recipients: case series and review of the literature. Pharmacotherapy: The Journal of Human Pharmacology and Drug Therapy. 2017;37(10):1258-71.

59. Zamora M. Clinical manifestations, diagnosis, and treatment of cytomegalovirus infection in lung transplant recipients. In: Blumberg EH, Martin, ed. UpToDate. Waltham, MA: UpToDate; 2019.

60. Kaul DR, Stoelben S, Cober E, et al. First report of successful treatment of multidrug-resistant cytomegalovirus disease with the novel anti-CMV compound AIC246. Am J Transplant Off J Am Soc Transplant Am Soc Transplant Surg. 2011;11(5):1079-84.

61. Razonable RR, Humar A. Cytomegalovirus in solid organ transplant recipients-guidelines of the American Society of Transplantation Infectious Diseases Community of Practice. Clin Transpl. 2019:e13512.

62. Bonatti HJ, Sharma R, Sawyer RG. Surgical Site Infections in Solid Organ Transplantation.

63. Abbo LM, Grossi PA, Practice AICo. Surgical site infections: guidelines from the American Society of Transplantation Infectious Diseases Community of Practice. Clin Transpl. 2019: e13589.

Publisher's Note Springer Nature remains neutral with regard to jurisdictional claims in published maps and institutional affiliations. 